\title{
La tuberculose, un fléau d'avenir
}

L'éditorial du numéro de décembre de médecine/sciences [1] se terminait par l'observation que la médecine était loin d'en avoir fini, voire même ne pouvait en finir, avec la lutte contre tous les types de vie à l'origine de maladies humaines. Il était rappelé que l'on mourait plus, en 1991, de tuberculose qu'il y a vingt ans. En réalité, la tuberculose reste aujourd'hui l'une des maladies infectieuses responsable de la plus grande mortalité à travers le monde, estimée à environ trois millions de personnes par an. Ce chiffre, qui tendait à diminuer jusqu'en 1948, a recommencé à augmenter dans tous les pays, y compris les plus développés, à partir de 1980. Les causes de l'aggravation de l'endémie tuberculeuse sont triples. Premièrement, dans les pays où l'épidémie de SIDA fait des ravages, elle crée un terrain extraordinairement favorable au développement de formes gravissimes de tuberculose, emportant souvent les malades avant même que le diagnostic ne soit porté [2, 3]. Deuxièmement, des souches multirésistantes de Mycobacterium tuberculosis ont fait leur apparition, et ont même déjà provoqué plusieurs morts dans les prisons américaines [4]. Troisièmement, les pays développés ont eu tendance à baisser la garde vis-à-vis de cette affection. Non pas d'ailleurs qu'elle ait jamais été éradiquée, puisqu'elle est toujours demeurée une cause importante de mortalité dans les pays en voie de développement, mais sa morbidité était devenue marginale dans les pays riches qui n'y portaient donc pas plus d'intérêt qu'à tous ces fléaux parasitaires des régions équatoriales et tropicales qui, pour être la première cause de mortalité dans le monde, n'en représentent pas moins qu'un investissement extrêmement minime des dépenses de santé de la planète. Les pays ayant donc la capacité de mener une recherche biologique et thérapeutique n'ont pas concentré beaucoup d'efforts sur ce germe, n'ont pas cherché à développer de même se sont montrés d'un laxisme coupable quant au suivi des malades et aux efforts consentis afin que ceuxci n'interrompent pas prématurément leur traitement. La multiplication des cas mal traités a donc probablement sélectionné des souches résistantes alors qu'aucune drogue nouvelle ne pouvait leur être opposée et alors que les connaissances biologiques sur cette bactérie avaient pris un tel retard qu'il n'était pas envisageable de réagir rapidement. Pour être juste, il faut ajouter aux raisons objectives de la situation actuelle les difficultés intrinsèques de la recherche sur $M$. tuberculosis. Il n'existe pas de vrai modèle animal de cette maladie, sa croissance en culture est extrêmement faible, ce qui fait que toute recherche à son propos promet d'être longue et pénible, et ne favorise pas le recrutement de jeunes chercheurs prêts à s'atteler à des investigations moins propices que d'autres à l'obtention rapide de succès "à la mode ". Les outils disponibles pour faire face rapidement à la gravité de la situation sont ainsi très limités [4]. Peut-être peut-on simplement noter la récente description d'un test d'amplification du génome de $M$. tuberculosis par PCR, aboutissant à un diagnostic extrêmement rapide, de nature à entreprendre un traitement sans délai... si tant est que l'on dispose de médicaments actifs [4].

A. $\mathbf{K}$.

1. Kahn A. Une année de médecine et sciences. médocine/sciences $1991 ; 7: 1014-5$.

2. Barnes PF, Bloch AB, Davidson PT, Snider DE. Tuberculosis in patients with human immunodeficiency virus infection. $N$ Engl J Med 1991; 324: 1644-50.

3. Harries AD. Tuberculosis and human immunodeficiency virus infection in developing countris. Lancet $1990 ; 335$ : 387-90.

4. Weiss R. On the track of "killer " EB. Srience 1992 ; 255: 148-50.
- COLLĖGe DE FRANCE •

\section{CHAIRE DE NEUROPHARMACOLOGIE}

M. Jacques Glowinski, professeur Année 1991-1992

Le cours de cette année sera reporté à une date ultérieure

\section{Séminaires :}

\section{Neurogénétique}

3 mars :

16 h 30 J. Feingold (Paris) Génétique formelle et neurogénétique.

17 h 30 B. Jordan (Marseille) Programmes "génome humain " à travers le monde : pourquoi, comment, quelles conséquences?

10 mars :

$16 \mathrm{~h} 30 \mathrm{~J}$. -L. Mandel (Strasbourg) Le syndrome du chromosome $x$ fragile: mécanismes génétiques d'une cause fréquente de retard mental.

17 h 30 J.-F. Foncin (Paris) Génétique et maladie d'Alzheimer.

17 mars :

$16 \mathrm{~h} 30$ A. Lombes (Paris) Mutations de I'ADN mitochondrial et pathologie humaine.

17 h $30 \mathrm{~J}$. Mallet (Gif-sur-Yvette) Génétique et psychiatrie.

24 mars :

16 h 30 H. Cann (Paris) Ataxie spinocérébelleuse (AOPC) : génétique moléculaire.

17 h 30 C. Sotelo (Paris) Mutations neurologiques affectant le cervelet de la souris et la synaptogenèse.

L'Administrateur du Collège de France André Miquel 